\title{
Cardiac Manifestation of the Patients with Novel Wuhan Coronavirus Infection: A Clinical Summary on Patients in the First Month of Outbreak
}

\author{
Pathum Sookaromdee ${ }^{1^{*}}$ and Viroj Wiwanitkit ${ }^{2}$ \\ ${ }^{1}$ TWS Medical Center, Bangkok, Thailand \\ ${ }^{2}$ Hainan Medical University, Haikou, China \& Dr. DY Patil University, Pune, India
}

\section{Dear Editor,}

In December 2019, a new emerging viral disease was firstly reported from Wuhan, China. The novel corona virus infection is a new febrile illness that is associated with pneumonia [1]. The disease has already been reported outside China mainland [2]. This new viral disease is the latest public health concern worldwide [1-2]. As a new emerging disease, limited knowledge of clinical aspect leads to difficulty in disease control and management. In clinical cardiology, it is questionable whether this new emerging disease has any cardiac problem. Indeed, a new corona virus infection might be associated with cardiac presentation (such as seen in Middle East Respiratory Syndrome (MERS) [3]). However, there is still no knowledge for the newest corona virus disease. Based on available data on 42 cases (until January 18, 2020), confirmed for infection during the first phase of disease emergence [1-2], there was no case with cardiac presentation. However, additional data from new report showed that some patients, about $12 \%$, might have clinical feature of acute cardiac injury [4]. Nevertheless, no data is available on cardiac pathology and there is also no explanation on the pathophysiology. At present, there are insufficient references to support the statement of cardiac manifestation associated with the new infection. The hypothesis that the new disease might have clinical association with cardiac problem might be raised. The observation on severe manifestation of the new corona virus infection in patients with underlying cardiac disease or cardiac related complications can be good supportive evidence. Based on the available data at present, cardiac problem is still not an important clinical problem among patients with novel Wuhan corona virus infection.

\section{CONFLICT OF INTEREST}

The authors declare no conflict of interest.

\section{ACKNOWLEDGEMENTS}

Declared none.

\section{REFERENCES}

1. Hsia W. Emerging new coronavirus infection in Wuhan, China: situation in early 2020. Case Study Case Rep 2020; 10: 8-9.

2. Yasri S, Wiwanitkit V. Editorial: Wuhan coronavirus outbreak and imported case. Adv Trop Med Pub Health Int 2019; 9: 1-2.

3. Wiwanitkit V. Cardiac problem and MERS. Anatol J Cardiol 2015; 15(10): 858

4. Huang C, Wang Y, Li X, Ren L, Zhao J, Hu Y, et al. Clinical features of patients infected with 2019 novel coronavirus in Wuhan, China. Lancet 2020; 395: 497-506.

\footnotetext{
*Corresponding Author: Pathum Sookaromdee, TWS Medical Center Bangkok, Thailand; Email: pathumsook@gmail.com

Received: January 01, 2020; Revised: February 14, 2020; Accepted: March 18, 2020

DOI: https://doi.org/10.37184/lnjpc.2707-3521.1.15
} 